University of New Hampshire

University of New Hampshire Scholars' Repository

Space Science Center

Institute for the Study of Earth, Oceans, and

Space (EOS)

1994

\title{
COMPTEL observations of gamma-ray flares in October 1991
}

\author{
$M$ Varendorff \\ University of New Hampshire - Main Campus \\ D J. Forrest \\ University of New Hampshire - Main Campus \\ Mark L. McConnell \\ University of New Hampshire - Main Campus, mark.mcconnell@unh.edu \\ James M. Ryan \\ University of New Hampshire, James.Ryan@unh.edu \\ R Suleiman \\ University of New Hampshire - Main Campus
}

See next page for additional authors

Follow this and additional works at: https://scholars.unh.edu/ssc

Part of the Astrophysics and Astronomy Commons

\section{Recommended Citation \\ COMPTEL observations of gamma-ray flares in October 1991 Varendorff, M. and Forrest, D. and McConnell, M. and Ryan, J. and Suleiman, R. and Diehl, R. and Lichti, G. and Rank, G. and Schönfelder, V. and Bennett, K. and Hanlon, L. and Winkler, C. and Swanenburg, B. N., AIP Conference Proceedings, 294, 55-58 (1994), DOl:http://dx.doi.org/10.1063/1.45200}

This Conference Proceeding is brought to you for free and open access by the Institute for the Study of Earth, Oceans, and Space (EOS) at University of New Hampshire Scholars' Repository. It has been accepted for inclusion in Space Science Center by an authorized administrator of University of New Hampshire Scholars' Repository. For more information, please contact Scholarly.Communication@unh.edu. 


\section{Authors}

M Varendorff, D J. Forrest, Mark L. McConnell, James M. Ryan, R Suleiman, R Diehl, G G. Lichti, G Rank, V Schonfelder, K Bennett, L O. Hanlon, C Winkler, and B Swanenburg 


\section{AIP | Proceedings}

\section{COMPTEL observations of gammaray flares in October 1991}

M. Varendorff, D. Forrest, M. McConnell, J. Ryan, R. Suleiman, R. Diehl, G. Lichti,

G. Rank, V. Schönfelder, K. Bennett, L. Hanlon, C. Winkler, and B. N. Swanenburg

Citation: AIP Conference Proceedings 294, 55 (1994); doi: 10.1063/1.45200

View online: http://dx.doi.org/10.1063/1.45200

View Table of Contents:

http://scitation.aip.org/content/aip/proceeding/aipcp/294?ver=pdfcov

Published by the AIP Publishing

\section{Articles you may be interested in}

OSSE observations of the 4 June 1991 solar flare

AIP Conf. Proc. 294, 15 (1994); 10.1063/1.45214

Observations of the 1991 June 11 solar flare with COMPTEL

AIP Conf. Proc. 294, 100 (1994); 10.1063/1.45207

Neutron and gammaray measurements of the solar flare of 1991 June 9

AIP Conf. Proc. 294, 89 (1994); 10.1063/1.45205

COMPTEL's solar flare catalog

AIP Conf. Proc. 294, 51 (1994); 10.1063/1.45199

Xray and gammaray observations of solar flares by GRANAT

AIP Conf. Proc. 294, 3 (1994); 10.1063/1.45197 
M. Varendorff, D. Forrest, M. McConnell, J. Ryan, R. Suleiman University of New Hampshire, Institute for the Study of Earth, Oceans and Space, Durham NH 03824, USA

R. Diehl, G. Lichti, G. Rank, V. Schönfelder

Max-Planck Institut für extraterrestrische Physik, D-8046 Garching, FRG

K. Bennett, L. Hanlon, C. Winkler

Astrophysics Division, Space Science Department of ESA, ESTEC

2200 AG Noordwijk, The Netherlands

B.N. Swanenburg

SRON-Leiden, P.B. 9504, NL-2300 RA Leiden, The Netherlands

\section{ABSTRACT}

The COMPTEL experiment on GRO images $0.75-30 \mathrm{MeV}$ celestial gammaradiation that falls within its 1 steradian field of view. During observation 12 (primary target (en A) in October 1991 the sun had been in the fov and several solar flares associated with the active region 6891 had been observed. Time profile and energy spectra had been produced, using COMPTEL's primary mode of operation (the telescope mode). Additionally the number of counts received in the D2-single burst detector (the secondary mode of operation) are given. We summarize the preliminary results on all of these flares.

\section{INTRODUCTION}

The imaging Compton Telescope, COMPTEL, onboard NASA's Compton Gamma Ray Observatory is a powerful tool for studying both the photon and neutron emission from energetic solar flares ${ }^{1,2}$. Since shortly after its launch in April 1991, COMPTEL has observed a number of solar flares, including the flares on June 9, 11 and $15,1991^{3,4}$.

In COMPTEL's imaging telescope or 'double scatter' mode $(0.75-30 \mathrm{MeV})$, it measures both positions and spectra of cosmic $\gamma$-ray sources that fall within its 1 steradian field of view. A pulse shape discrimination and time of flight measurement allows the separation between $\gamma$-rays and neutrons. In addition, in burst or 'single detector' mode COMPTEL accumulates independent $0.1-1.1 \mathrm{MeV}$ and $1-10 \mathrm{MeV}$ spectra in two of its lower Nal detectors.

In COMPTEL's 'double scatter' mode, a photon which Compton-scatters in one of the seven upper D1 detectors, is then detected in one of the lower fourteen high-Z D2 detectors. In the simplest case of a single Compton scatter in D1 and complete absorption in D2, the possible $\gamma$-ray source positions lie on a circle of radius $\bar{\varphi}$ around the direction of the scattered photon, with

$$
\cos \bar{\varphi}=1-\frac{1}{\epsilon_{2}}+\frac{1}{\epsilon_{1}+\epsilon_{2}}
$$

where $\epsilon_{1}$ and $\epsilon_{2}$ are the energy deposits measured in the upper (D1) and lower (D2) detectors, respectively (in units of the electron rest-mass). In the case of solar flares, 
the position of the source is known and the location information is used for event selection to suppress the background. This also allows us to compile a spectrum, where events from the sun with only partly absorption in the lower D2-detector are suppressed, leading to a nearly diagonal response.

A descritption of the 'single mode' together with a catalog of spectra obtained from solar flares can be found in these proceedings".

\section{DATA and ANALYSIS}

In October 1991 the sun was in a very active phase and produced several Xclass flares. Comptel registered 9 solar flares in its 'single mode' in October 1991. During observation period 12 from October 17 to 31,1991 , the sun was in the field of view of the telescope. The instrument was pointed towards the Cen-A region on the sky. BATSE registered several hundred solar flares during this time. For the stronger ones we produced time profiles of the COMPTEL data. We used the flare onset time and duration measured by BATSE, to select an appropriate time window. Only telescope events which satisfy the optimum event selection criteria, and which were consistent with the solar position, were used.

If the time profile showed evidence for the presence of a flare signal, an image was produced, to verify, that the signal is coming from the direction of the sun.

\section{RESULTS}

In Figure 1 we display the raw time profiles (not yet deadtime corrected) of 5 solar flares.

Two of the flares, 24.10.91 2:36:21 and 27.10.91 5:36:23, were so intense, that the instrument showed severe deadtime effects up to $90 \%$. For the flare on 24.10 .91 16:53:22s the instrument was shut off shortly after the onset of the flare because of a SAA passage. The flare on $30.10 .916: 16: 18$ occured just $\sim 200$ seconds after the SAA pass of the satellite. In figure 2 we show the energy loss spectra of two solar flares. For information on the background in the energy histograms, the measured countrate 15 orbits earlier and 15 orbits later is given. These orbits can be used as a good first estimate of the background count rate. For the flare of 27.10.91 5:39:35s the real background will be lower, because of the mentioned deadtime effect.

Table 1. Summary of the observed solar flares

\begin{tabular}{ccccc}
\hline $\begin{array}{c}\text { Flare } \\
\text { (date) }\end{array}$ & $\begin{array}{l}\text { onset } \\
\text { time (UT) }\end{array}$ & class & $\begin{array}{c}\text { duration } \\
\text { (s) }\end{array}$ & $\begin{array}{c}\text { telescope } \\
\text { src/bkg }\end{array}$ \\
\hline 24.10. & $2: 37: 10$ & $\times 2.1$ & 110 & $181 / 5$ \\
24.10. & $16: 54: 15$ & $\mathrm{M} 3.2$ & 25 & $74 / 35$ \\
27.10. & $2: 7: 30$ & $\times 1.9$ & 140 & $610 / 65$ \\
27.10. & $5: 39: 35$ & $\times 6.1$ & 375 & $614 / 50$ \\
30.10. & $6: 16: 18$ & $\times 6.1$ & 1650 & $1357 / 600$ \\
\hline
\end{tabular}

We summarize our results in Table 1. For each flare the onset time and duration of the impulsive phase in the energy range from 0.72 to $30 \mathrm{MeV}$ is given. Furthermore the total number of counts and the estimated number of background counts in the 'telescope mode' during the impulsive phase of the flares are given. A 

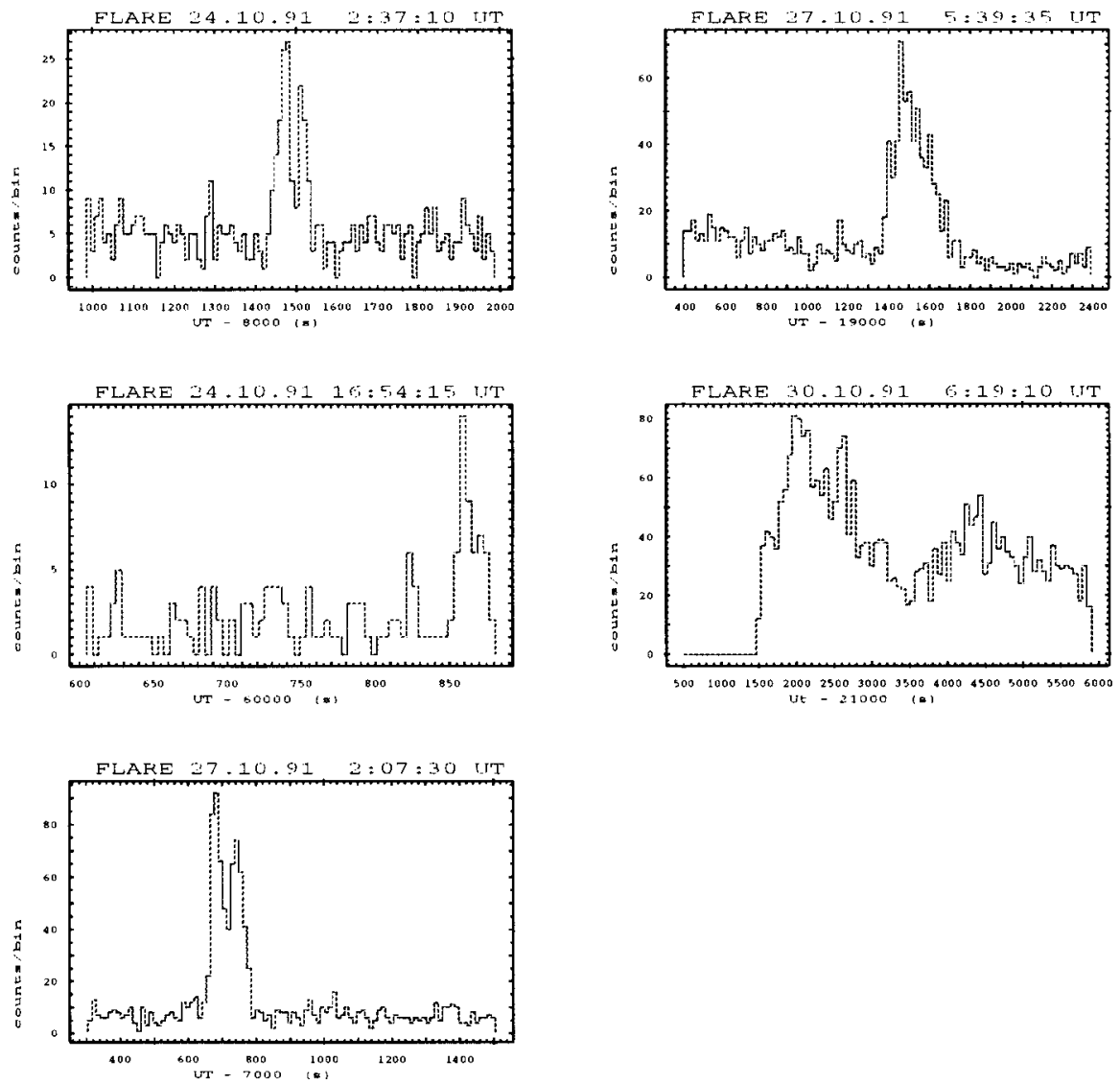

Figure 1. Time profiles of solar flares detected in COMPTEL telescope mode.

more detailed study of the background is still in progress. This should allow us to better define the extent of the $\gamma$-ray emission.

\section{SUMMARY}

This paper reports on the preliminary results of the analysis of 10 solar flares during an observation in Ocotber 1991. For the time profiles and spectra only data from COMPTEL's telescope mode were used. The total number of counts from solar flares using the single detector mode are given as well. Results from spectral studies and analysis from neutrons from solar flares in June 1991 and a catalog of preliminary spectra and countrates from the single detector mode data can be found in these proceedings. 

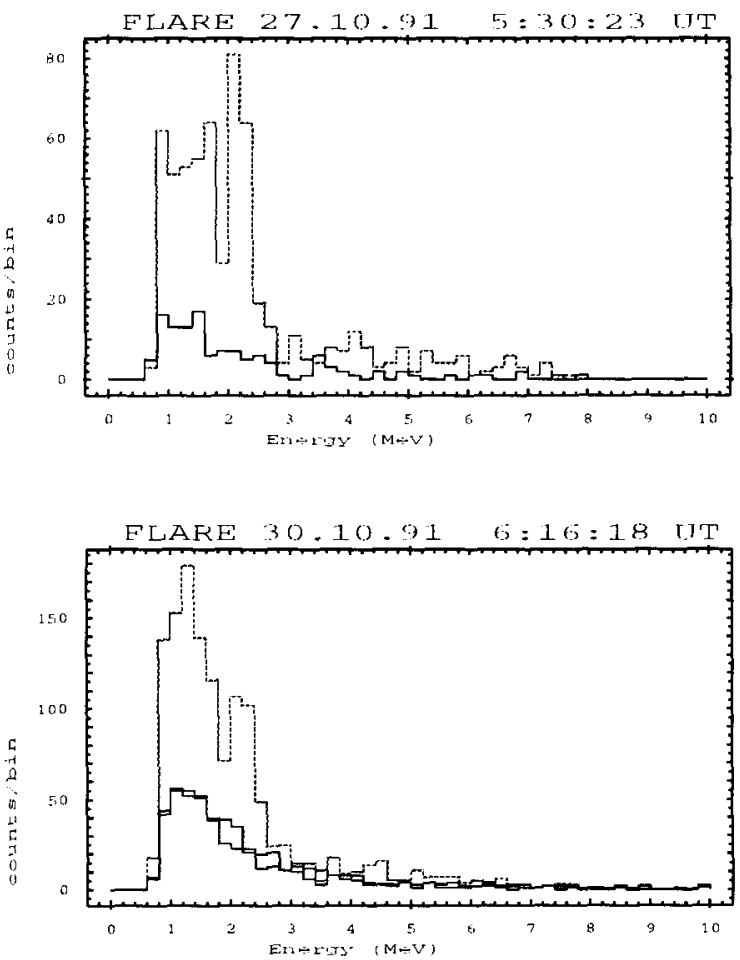

Figure 2. Energy loss spectra of solar flares with background spectrum overlayed.

\section{REFERENCES}

1. Schönfelder, V. et al. , Ap. J. Suppl. (in press, 1993).

2. Ryan, J. et al. , Data Analysis in Astronomy IV, ed. V. diGesu et al., Plenum Press, New York 261 (1992).

3. McConnell, M. et al. , COSPAR E.3-S.5.06 (1992).

4. Rank, G., et al. , COMPTON Symposium, Washington University, St. Louis, (October 1992).

5. Suleiman, R., et al. , Conference on High Energy Emission from Solar Flares, Waterville Valley, N.H., USA, (March 1993, in press). 